\title{
Is changing hypothalamic activity important for control of ovulation?
}

\author{
R N CLAYTON, J P ROYSTON, J CHAPMAN, M WILSON, M OBHRAI, R S SAWERS, \\ S S LYNCH
}

\begin{abstract}
The activity of the hypothalamic gonadotrophin releasing hormone pulse generator in women with regular ovulatory and anovulatory menstrual cycles was assessed to see whether changes therein are important determinants of normal and impaired ovarian function. Endogenous gonadotrophin releasing hormone secretion was inferred by measurement of the pituitary luteinising hormone response by characterisation of pulsatile luteinising hormone release over eight hours on three occasions during the course of follicular development and once during the luteal stage of the same cycles.

In 13 ovulatory cycles (serum progesterone concentration $>25 \mathrm{nmol} / \mathrm{l}$ ) confirmed by ovarian ultrasonography a pronounced variability in luteinising hormone pulse patterns among subjects was compatible with ovulation. In the luteal stage of ovulatory cycles the luteinising hormone interpeak interval ( $85 \mathrm{~min}$, range 42-125) was significantly longer than that during the early follicular (64 $\mathrm{min}, 40-103$ ), mid-follicular (62 $\mathrm{min}, 37-107$ ), and late follicular ( $59 \mathrm{~min}, 39-80$ ) stages of the same cycles. Thus in ovulatory cycles no increase in frequency of the gonadotrophin releasing hormone pulse generator was detected during follicular development, though this activity decreased in the luteal stage.

In five late follicular stage studies in which part of the preovulatory luteinising hormone surge was captured no change in pulse frequency of luteinising hormone was detected
\end{abstract}

Clinical Research Centre, Harrow, Middlesex HA1 3UJ

R N CLAYTON, MD, FRCP, head of endocrinology

J P ROYSTON, MSC, MIS, statistician, member of scientific staff

University of Birmingham

J CHAPMAN, MRCP, senior registrar in medicine

M WILSON, BSC, research technician, department of medicine

M OBHRAI, MRCOG, senior lecturer in obstetrics and gynaecology

R S SAWERS, MRCOG, consultant obstetrician and gynaecologist

Department of Clinical Endocrinology, Women's Hospital, Birmingham

S S LYNCH, BSC, PHD, top grade biochemist

Correspondence to: Dr Clayton. compared with the mid-follicular stage of the same cycles or when compared with the late follicular stage of other cycles when no luteinising hormone surge was captured. Though mean luteinising hormone concentrations in luteinising hormone surge series (36 IU/1) were high, the amplitude of luteinising hormone pulses (165\%) was only slightly greater than during non-surge late follicular stage studies (145\%). Hence no change in hypothalamic gonadotrophin releasing hormone activity is required to generate the preovulatory discharge of luteinising hormone in man, which occurs as a result of the sensitising action of rising oestradiol concentrations on pituitary responsiveness to the same hypothalamic input signal.

Luteinising hormone pulse frequency, peak amplitude, and mean serum luteinising hormone concentrations in seven anovulatory cycles (progesterone concentration $<10 \mathrm{nmol} / \mathrm{l}$ ) were not different from those at comparable stages of ovulatory cycles. These data suggest that the primary abnormality in this group of regularly menstruating anovulatory women lies in the ovary rather than in the hypothalamic control of the anterior pituitary.

\section{Introduction}

It is now well established that secretion of pituitary gonadotrophins (luteinising hormone and follicle stimulating hormone) is episodic in response to short lived discharges of gonadotrophin releasing hormone from the hypothalamus. ${ }^{12}$ Gonadotrophin releasing hormone cannot be measured reliably in peripheral plasma, so the activity of the hypothalamic gonadotrophin releasing hormone pulse generator is analysed indirectly by assessing the magnitude and frequency of serum luteinising hormone pulses. Some reports have suggested that physiological changes occur in the activity of the hypothalamic gonadotrophin releasing hormone pulse generator in both men and women. ${ }^{3}$

Of recent interest has been whether hypothalamic gonadotrophin releasing hormone secretory activity increases during follicular maturation and, more particularly, whether it contributes to the initiation and maintenance of the preovulatory discharge of luteinising hormone. Several studies suggest that the pulse frequency of luteinising hormone increases from the early to late 
follicular stages of the menstrual cycle, ${ }^{47}$ though there is still debate about changes in luteinising hormone pulse frequency at the time of the preovulatory luteinising hormone surge.$^{6-9}$ Knobil argued that there was no need for modulation of the output of gonadotrophin releasing hormone and that the surge of luteinising hormone occurred primarily as a consequence of oestrogen sensitisation of the pituitary response to an unvarying gonadotrophin releasing hormone signal. ${ }^{1}$ This view is adequately supported by studies in man in which normal ovulatory cycles and conceptions occurred reproducibly with unvarying frequency and amplitude of pulsatile doses of gonadotrophin releasing hormone. ${ }^{1011}$ Nevertheless, we are still unclear whether alterations in gonadotrophin releasing hormone pulse generator activity in spontaneous ovulatory menstrual cycles have any physiological relevance. In only two series were the same subjects studied at different stages of the same cycle, and then only twice during the follicular stage. ${ }^{68}$

The present longitudinal study, as opposed to previous cross sectional ones, was designed to assess the same subject at three defined stages of follicular development and once in the luteal stage of the cycle, primarily to see whether the pulse frequency of luteinising hormone increased with follicular maturation during ovulatory menstrual cycles. We also report on the secretory dynamics of luteinising hormone in women with anovulatory but regular menstrual cycles to ascertain whether abnormalities in the gonadotrophin releasing hormone pulse generator might contribute to the mechanism of anovulation.

\section{Subjects and methods}

Informed consent was obtained from normal healthy female volunteers aged 19-31 drawn from staff of the University of Birmingham who gave a history of regular menstruation (see table I). Subjects were between $90 \%$ and $112 \%$ of ideal body weight and none engaged in strenuous physical exercise. All subjects with presumed ovulatory cycles had serum progesterone concentrations of $>25 \mathrm{nmol} / 1$ during the second half of two or more cycles immediately preceding the study cycle. Subjects with regular menstrual cycles but no evidence of ovulation had serum progesterone values of $<10 \mathrm{nmol} / 1$ during the second half of two or more preceding cycles. These anovulatory subjects did not have polycystic ovary syndrome-that is, they were not hirsute, were not overweight, had luteinising hormone to follicle stimulating hormone ratios of $<2 \cdot 5: 1$ during the early follicular stage, and had no evidence of polycystic ovaries on ultrasonography. No subject had used hormonal contraceptives for at least six months before the study. The study was approved by the ethical committee of the Central Birmingham health district.

Protocol-To obtain evidence of ovulation and to time this as accurately as possible (within 24 hours) subjects had serial pelvic ultrasound scans performed. with a Diasonics DRF 100 sector scanner. Ovulation was presumed to have occurred when a single dominant follicle $(18-24 \mathrm{~mm}$ diameter) in one ovary collapsed within 24 hours of a preceding scan; this was defined as the day of ovulation (day 0 ). Studies in the early follicular stage were performed within three days of the onset of menstruation. Because of individual variation in cycle length subjects were studied when the diameter of a single follicle had reached 8-10 $\mathrm{mm}$ (mid-follicular stage) and $>16 \mathrm{~mm}$ (late follicular stage) rather than on predetermined days of the cycle. An indwelling venous cannula was inserted into the forearm and $4 \mathrm{ml}$ blood withdrawn every 10 minutes for eight hours beginning between 0900 and 1000.

Hormone assays-Luteinising hormone was measured by double antibody radioimmunoassay and values expressed in terms of the MRC $68 / 40$ standard. All samples from the four study days in one subject were assayed in duplicate in the same assay. A serum pool comprising an aliquot of each sample was used for single measurements of mean integrated follicle stimulating hormone, oestradiol, and progesterone concentrations by radioimmunoassays described elsewhere. "The same pool was used to determine the luteinising hormone intra-assay coefficient of variation. Lower limits of detection were: luteinising hormone and follicle stimulating hormone $1 \mathrm{IU} / 1$, oestradiol $40 \mathrm{pmol} / 1$, and progesterone $0.5 \mathrm{nmol} / 1$; and interassay coefficients of variation were: follicle stimulating hormone $5 \cdot 3 \%$ at $8 \mathrm{IU} / \mathrm{l}$ and $13.5 \%$ at $3 \mathrm{IU} / \mathrm{l}$, oestradiol $12 \%$, and progesterone $16 \%$.

Luteinising hormone assay variability, peak detection, and statistical analysis_A simple equation (see appendix) allowed a reliable estimate of the within assay variability of luteinising hormone measurement for any value in a particular cycle, which was essential for the success of our peak detection method. We constructed our own computer algorithm (see appendix) to detect and count peaks and calculate their amplitudes and intervals, published methods ${ }^{612-14}$ being unsatisfactory when applied to our data. In principle a peak was defined as a value that was greater than the minima (nadirs) on either side to an extent unlikely to have occurred by chance, given the known random component of the data (within assay variability). All hormone values were log transformed before analysis. Differences between groups (ovulatory versus anovulatory) in oestradiol, progesterone, and follicle stimuating hormone concentrations were assessed by analysis of variance for the four cycle stages separately, allowing for possible differences among subjects. Luteinising hormone profile characteristics were subjected to analysis of variance and subsequent $t$ tests in order to determine differences between groups and among stages, allowing for differences among subjects and cycles. Peak amplitude and interpeak interval were log transformed to reduce skewness. Analysis of variance for number of peaks per eight hours was carried out assuming a Poisson distribution; further analysis of differences among cycle stages used the Wilcoxon signed ranks matched pairs test. Series capturing part of the luteinising hormone surge (mean luteinising hormone concentration $>25 \mathrm{IU} / \mathrm{l}$ ) as compared with those not covering the luteinising hormone surge in the late follicular stage of ovulatory cycles were analysed as a separate subgroup by unpaired or paired $t$ test.

\section{Results}

\section{CYCLE CHARACTERISTICS}

Ten women aged 20-31 were studied longitudinally on four occasions during ultrasonographically and hormonally confirmed ovulatory cycles. Three of these subjects were studied during a second cycle. We also studied six women aged 19-20 with anovulatory cycles, as judged by ovarian ultrasonography and serum progesterone concentrations of $<10 \mathrm{nmol} / \mathrm{l}$; one of these subjects was studied during a second cycle. Table I gives the characteristics of the two study groups. The younger, anovulatory group had more variable cycle lengths, both among and within subjects, than had the regular ovulators.

Mean serum oestradiol concentrations were significantly $(p<0.05)$ lower in the anovulatory group at all stages of the cycle (table I). Though the ovaries of some of the women with anovulatory cycles contained cystic

TABLE I-Subject and cycle characteristics and serum hormone concentrations on days of 10 minute sampling

\begin{tabular}{|c|c|c|c|c|c|c|c|c|c|c|c|c|c|c|}
\hline & \multirow{2}{*}{$\begin{array}{c}\text { Age } \\
\text { of } \\
\text { subjects } \\
\text { (years) }\end{array}$} & \multirow{2}{*}{$\begin{array}{c}\text { Length } \\
\text { of } \\
\text { cycle } \\
\text { (days) }\end{array}$} & \multicolumn{3}{|c|}{ Early follicular stage } & \multicolumn{3}{|c|}{ Mid-follicular stage } & \multicolumn{3}{|c|}{ Late follicular stage } & \multicolumn{3}{|c|}{ Luteal stage/second half of cycle } \\
\hline & & & $\begin{array}{c}\text { Oestradiol } \\
(\mathrm{pmol} / \mathrm{l})\end{array}$ & $\begin{array}{c}\text { Progesterone } \\
(\mathrm{nmol} / \mathrm{l})\end{array}$ & $\begin{array}{l}\text { FSH } \\
\text { (IU/l) }\end{array}$ & $\begin{array}{c}\text { Oestradiol } \\
(\mathrm{pmol} / \mathrm{l})\end{array}$ & $\begin{array}{c}\text { Progesterone } \\
(\mathrm{nmp} / /)\end{array}$ & $\begin{array}{l}\text { FSH } \\
(\text { IU/I) }\end{array}$ & $\begin{array}{c}\text { Oestradial } \\
(\mathrm{pmo} / \mathrm{l})\end{array}$ & $\begin{array}{l}\text { Progesterone } \\
(\mathrm{nmol} / \mathrm{)})\end{array}$ & $\begin{array}{l}\text { FSH } \\
\text { (IU//) }\end{array}$ & $\begin{array}{l}\text { Oestradiol } \\
(\mathrm{pmol} / \mathrm{l})\end{array}$ & $\begin{array}{l}\text { Progesterone } \\
(\mathrm{nmol} / \mathrm{l})\end{array}$ & $\begin{array}{l}\text { FSH } \\
(\mathrm{IU} / \mathrm{l})\end{array}$ \\
\hline \multicolumn{15}{|c|}{ Ovulatory cycles ( 10 subjects, 13 cycles) } \\
\hline $\begin{array}{l}\text { Meant } \\
\text { SEM } \\
\text { Range }\end{array}$ & $\begin{array}{r}26 \cdot 6 \\
1.0 \\
20-31\end{array}$ & $\begin{array}{c}27 \cdot 7 \\
0 \cdot 6 \\
24-31\end{array}$ & $\begin{array}{c}168 \\
14 \\
90-240\end{array}$ & $\begin{array}{l}3 \cdot 0 \\
0 \cdot 3 \\
1-5\end{array}$ & $\begin{array}{l}3.9 \\
0.3 \\
3-6\end{array}$ & $\begin{array}{c}282 \\
26 \\
150-470\end{array}$ & $\begin{array}{l}2.9 \\
0.6 \\
1-10\end{array}$ & $\begin{array}{l}3 \cdot 7 \\
0 \cdot 3 \\
2-6\end{array}$ & $\begin{array}{c}892 \\
86 \\
420-1330\end{array}$ & $\begin{array}{l}2 \cdot 4 \\
0.4 \\
1-5\end{array}$ & $\begin{array}{l}5 \cdot 3 \\
1 \cdot 1 \\
2 \cdot 14\end{array}$ & $\begin{array}{c}490 \\
38 \\
280-700\end{array}$ & $\begin{array}{c}50 \cdot 5 \\
3.5 \\
28-64\end{array}$ & $\begin{array}{l}2 \cdot 2 \\
0 \cdot 2 \\
1-3\end{array}$ \\
\hline \multicolumn{15}{|c|}{ Anovulatory cycles (six subjects, seven cycles) } \\
\hline $\begin{array}{l}\text { Mean† } \\
\text { SEM } \\
\text { Range }\end{array}$ & $\begin{array}{r}19 \cdot 7 \\
0 \cdot 2 \\
19-20\end{array}$ & $\begin{array}{c}30 \cdot 0 \\
1.4 \\
26-37\end{array}$ & $\begin{array}{c}124^{\star} \\
20 \\
60-220\end{array}$ & $\begin{array}{l}2.5 \\
0.8 \\
1-6\end{array}$ & $\begin{array}{l}2 \cdot 7 \star \\
0.5 \\
1-5\end{array}$ & $\begin{array}{c}173^{\star} \\
21 \\
100-260\end{array}$ & $\begin{array}{l}1 \cdot 7 \\
0.4 \\
1-4\end{array}$ & $\begin{array}{l}4 \cdot 3 \\
0 \cdot 6 \\
2-7\end{array}$ & $\begin{array}{c}320 \star \star \\
47 \\
120-510\end{array}$ & $\begin{array}{l}2 \cdot 1 \\
0.6 \\
1-5\end{array}$ & $\begin{array}{l}4 \cdot 6 \\
0.6 \\
3-7\end{array}$ & $\begin{array}{c}207 \star \star \\
28 \\
120-330\end{array}$ & $\begin{array}{l}5 \cdot 4^{\star \star \star} \\
1 \cdot 0 \\
2-10\end{array}$ & $\begin{array}{l}3.3 \\
0.8 \\
1-7\end{array}$ \\
\hline
\end{tabular}

FSH=Follicle stimulating hormone.

Compared with ovulatory cycles: ${ }^{\star} \mathrm{p}<0.05,{ }^{\star \star} \mathrm{p}<0.01$ (analysis of variance on $\log$ data).

†Except for age of subjects means are arithmetic over cycles studied. 
structures of comparable size to those of the ovulators, these apparently produced little oestradiol. Mean serum follicle stimulating hormone concentrations in the early follicular stage of ovulatory cycles were significantly $(p<0.05)$ higher than in anovulatory cycles. At other times in the cycle follicle stimulating hormone concentrations were similar in the two groups.

\section{QUALITATIVE CHARACTERISTICS OF PULSATILE LUTEINISING HORMONE SECRETION}

\section{Ovulatory cycles}

Figures 1 and 2 show examples of luteinising hormone pulse patterns in ovulatory cycles. The ordinate scale in the graphs is the same for all cycle stages, so that when absolute luteinising hormone values are very low a large percentage change does not appear as a striking peak, though in relative terms it is large. Generally the luteal stage showed broad peaks of high amplitude. Sometimes smaller amplitude, short duration (20 minute) peaks were apparent as the luteinising hormone concentration was falling (fig 2).

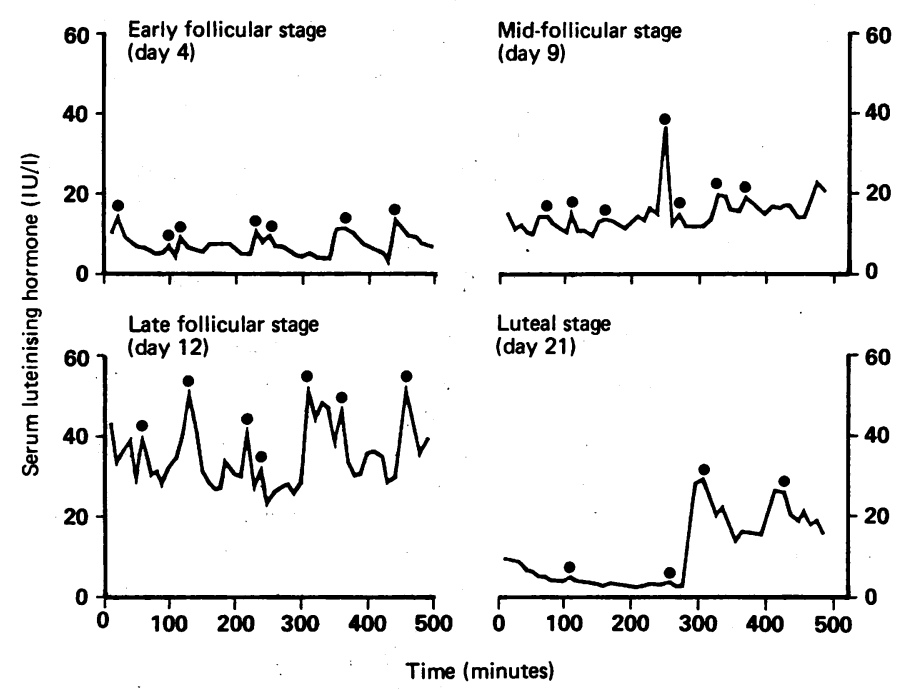

FIG 1-Luteinising hormone pulse patterns in ovulatory cycle capturing part of preovulatory luteinising hormone surge. Days in parentheses are days from onset of menstruation. = Luteinising hormone peak.

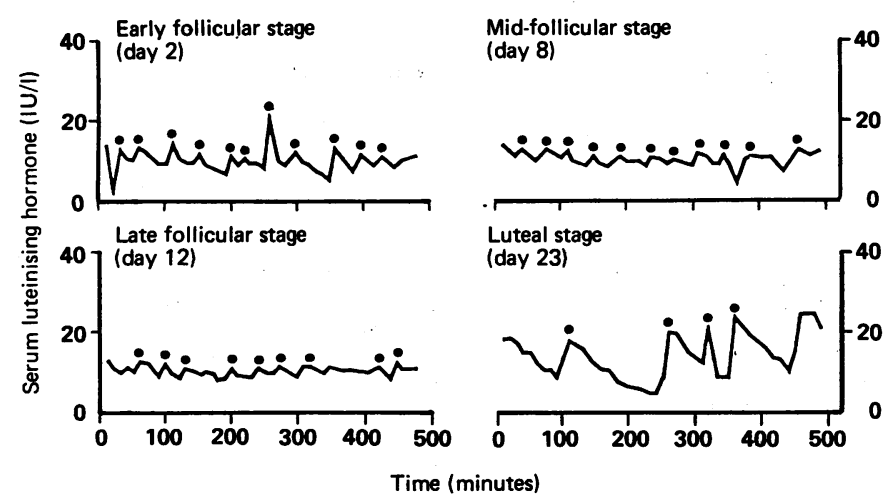

FIG 2-Luteinising hormone pulse patterns in ovulatory cycle when luteinising hormone surge was not captured. Days in parentheses are days from onset of menstruation. $=$ Luteinising hormone peak.

Periods of up to three hours with little or no pulsatile luteinising hormone release sometimes occurred during the luteal stage (fig 1 ). Nine of the 13 luteal stages conformed to this general pattern. In four luteal stages either short duration peaks of small amplitude predominated of very little luteinising hormone pulsatility was recorded.

The pulse pattern of luteinising hormone during the early follicular stage of ovulatory cycles (figs 1 and 2) was also variable, though in six cycles it was

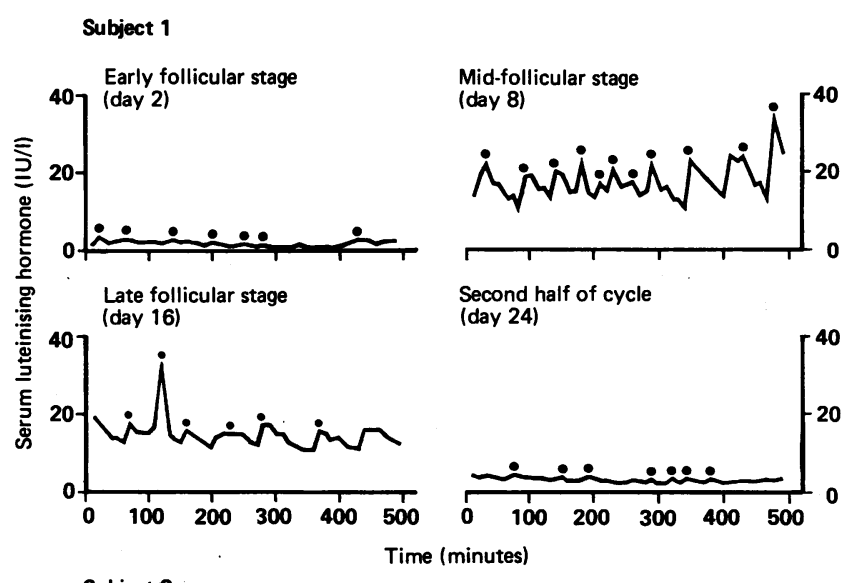

Subject 2

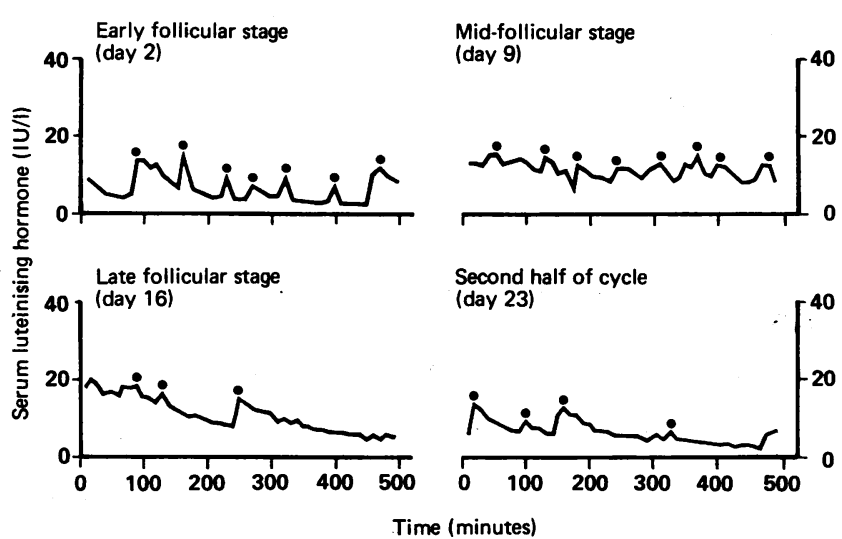

Subject 3

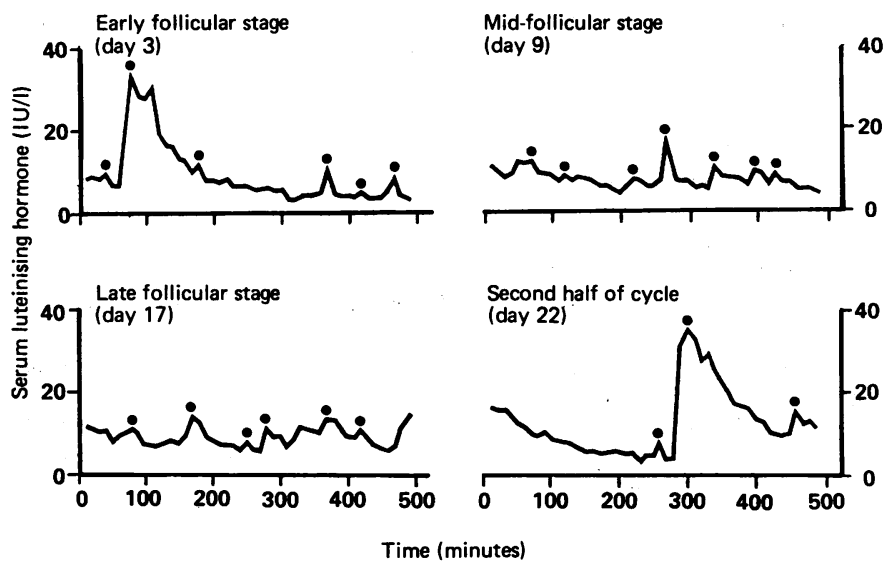

FIG 3-Luteinising hormone patterns in three cycles from anovulatory subjects. Days in parentheses are days from onset of menstruation. $=$ Luteinising hormone peak.

qualitatively similar to that of the luteal stage, with broad luteinising hormone peaks of moderate amplitude similar to those in figure 1 . In the other seven cycles peaks of short duration and small amplitude similar to those in figure 2 were seen. The mid-follicular stage was typified by small amplitude short duration pulses as shown in figure 2, though a more "spiky" pattern was found in three cycles (fig 1), and in a few cycles (three) there was almost no pulsatile luteinising hormone secretion during the sampling period (not shown).

The most striking change occurred in the late follicular stage of ovulatory cycles. In five of 11 studies in the late follicular stage part of the preovulatory luteinising hormone surge was captured (mean luteinising hormone concentration $>25 \mathrm{IU} / \mathrm{l}$ ). This occurred one to three days before the disappearance of the dominant follicle on the ultrasound scan. In all instances the luteinising hormone pattern was noticeably spiky (fig 1), though the average relative peak amplitude was no greater than during the mid-follicular stage because of the higher mean luteinising hormone values throughout the sampling period. In the remaining six studies in the late follicular stage the pattern of pulsatility was like that in the mid-follicular stage (fig 2). 


\section{Anovulatory cycles}

Figure 3 shows examples of luteinising hormone profiles from three anovulatory subjects with distinctly different patterns of ovarian morphology.

In subject 1 the cycle was characterised by formation of a follicular cyst (50 $\mathrm{mm}$ diameter) and poor oestrogen production (maximum serum oestradiol concentration $370 \mathrm{pmol} / \mathrm{l}$ ). Luteinising hormone pulses of discernible but very low amplitude were seen on days 2 and 24 of this cycle, but at the other times high frequency moderate amplitude luteinising hormone pulses characteristic of the mid-follicular and late follicular stages of ovulatory cycles were observed.

In subject 2 no cystic structures were seen in either ovary at any time during the cycle. The underlying pattern was of broad high amplitude pulses with additional short lower amplitude peaks on days 2,16 , and 23 , whereas on day 9 the pattern was more like that in the mid-follicular stage of ovulatory cycles.

In subect 3 a single cyst increasing to $17 \mathrm{~mm}$ diameter in the right ovary disappeared suddenly on day 17 , suggesting ovulation, but the serum oestradiol concentration was only $120 \mathrm{pmol} / \mathrm{l}$. Serum progesterone concentration was $4 \mathrm{nmol} / \mathrm{l}$ six days after disappearance of the cyst. The luteinising hormone pulse profile in this subject was very similar to that seen during ovulatory cycles, with broad high amplitude peaks on days 3 and 22 of the cycle but a typical mid-follicular and late follicular stage pattern on days 9 and 17 .

\section{QUANTITATIVE ANALYSIS OF LUTEINISING HORMONE PULSE PROFILES}

Analysis of variance for luteinising hormone pulse frequency, interpeak interval, and peak amplitude disclosed significant differences among cycle stages but not between groups (ovulatory versus anovulatory) (table II). At any given stage of the cycles mean values of these variables were similar in ovulatory and anovulatory cycles. The only significant difference in pulse frequency at any time during the follicular stage was in the anovulatory subjects, whose mean interpeak interval was 55 minutes in the mid-follicular stage compared with 69 minutes in the early follicular stage $(p<0.05)$. In the luteal stage of ovulatory cycles, however, the interpeak interval was longer at 85 minutes than at any other time during the follicular stage. The wide range of interpeak intervals and luteinising hormone pulse amplitudes reflects the large intersubject differences.

The luteinising hormone pulse amplitude was independent of the absolute luteinising hormone concentration and was similar (about $210 \%$ ) in the early follicular and luteal stages, though significantly $(p<0.05)$ higher than in the mid-follicular and late follicular stages $(160 \%)$. There was no difference in pulse amplitude between women with ovulatory and anovulatory cycles at any stage (table II). Though the mean luteinising hormone concentration in the preovulatory luteinising hormone surge profiles was $>25 \mathrm{IU} / 1$, there was no increase in pulse amplitude compared with the mid-follicular stage of the same cycles. When compared with the late follicular stage of cycles in which surge luteinising hormone values were not attained, however, a slightly greater amplitude was observed $(164 \% v 145 \% ; \mathrm{p}<0.04)$. There was no increase in luteinising hormone pulse frequency during that part of the luteinising hormone surge that was captured compared with the midfollicular stage of those same cycles or compared with the late follicular stage of non-surge cycles.

Mean eight hour serum luteinising hormone concentrations varied considerably among subjects (table II), there being no significant difference at any stage between ovulatory and anovulatory cycles. There was a significant $(p<0.05)$ increase in mean luteinising hormone concentration during the late follicular stage of ovulatory cycles compared with other stages, but this was attributable to the very high values contributed by the luteinising hormone surge cycles. When these five cycles were excluded from analysis no interstage differences were found.

The mean luteinising hormone to follicle stimulating hormone ratio during the early follicular stage of ovulatory cycles $(1 \cdot 8)$ was similar to that during anovulatory cycles $(2 \cdot 2)$.

\section{Discussion}

The object of this study was to see whether changes in hypothalamic gonadotrophin releasing hormone secretory activity are required for spontaneous ovulation. We assessed this indirectly by analysing luteinising hormone pulse frequency and amplitude in samples obtained at four different stages of the same menstrual cycle in healthy young women. This is the largest $(20$ cycles) such longitudinal study. A unique feature of our protocol was the study of subjects at similar stages of follicular development, when hormonal exposure of the gonadotrophin releasing hormone pulse generator would be more comparable among individuals than if subjects were studied arbitrarily on specified days of the cycle, when follicular size, and hence oestrogen production, ${ }^{15}$ might be more variable.

During the follicular stage of ovulatory cycles secretory episodes of hypothalamic gonadotrophin releasing hormone, as reflected by luteinising hormone interpulse interval, were similar to those in other series, ${ }^{5616} 17$ though shorter than that reported by Backstrom $e t$ $a l^{4}$ and Soules et $a l{ }^{18}$ This discrepancy is probably explicable on the basis of the 15 and 20 minute sampling intervals employed by Backstrom and Soules and coworkers, as it is now clear that reducing the frequency of sampling greatly reduces the interpulse interval observed. ${ }^{17}$ We were unable to detect any change in gonadotrophin releasing hormone secretion during the follicular stage of ovulatory cycles; this is in contrast with other reports, ${ }^{48}$ though in some instances any increase was marginal. ${ }^{56}$ The explanation may lie in the wider range of luteinising hormone interpulse intervals found in the early follicular stage as a consequence of profiles like the luteal stage in many instances. This pattern has not been highlighted before, though it is apparent in some published profiles. ${ }^{58}$ Though the relevance is not clear, the "luteal-like" profile during the early follicular stage may represen residual suppression of the gonadotrophin releasing hormone

TABLE II-Quantitative analysis of luteinising hormone profiles

\begin{tabular}{|c|c|c|c|c|c|c|c|c|c|c|}
\hline \multirow{2}{*}{\multicolumn{2}{|c|}{ Cycle stage }} & \multirow[b]{2}{*}{ No } & \multicolumn{2}{|c|}{ No of peaks/8 hours } & \multicolumn{2}{|c|}{ Interpeak interval (min) } & \multicolumn{2}{|c|}{ Peak amplitude (\% of mean nadir) } & \multicolumn{2}{|c|}{ Luteinising hormone (IU/l) } \\
\hline & & & Mean & Range & Mean & Range & Mean & Range & Mean & Range \\
\hline (A) Early follicular & $\left\{\begin{array}{l}\text { Ovulatory } \\
\text { Anovulatory }\end{array}\right.$ & $\begin{array}{r}13 \\
7\end{array}$ & $\begin{array}{l}7 \cdot 0 \\
6 \cdot 6\end{array}$ & $\begin{array}{l}4-11 \\
5-8\end{array}$ & $\begin{array}{l}64 \\
69\end{array}$ & $\begin{array}{l}40-103 \\
59-86\end{array}$ & $\begin{array}{l}200 \\
223\end{array}$ & $\begin{array}{l}135-388 \\
184-260\end{array}$ & $\begin{array}{l}7 \cdot 0 \\
6 \cdot 0\end{array}$ & $\begin{array}{l}2 \cdot 2 \cdot 13 \cdot 0 \\
1 \cdot 9-11 \cdot 6\end{array}$ \\
\hline (B) Mid-follicular & $\left\{\begin{array}{l}\text { Ovulatory } \\
\text { Anovulatory }\end{array}\right.$ & $\begin{array}{r}13 \\
7\end{array}$ & $\begin{array}{l}7 \cdot 5 \\
8 \cdot 7\end{array}$ & $\begin{array}{l}2-12 \\
7-11\end{array}$ & $\begin{array}{l}62 \\
55\end{array}$ & $\begin{array}{l}37-107 \\
45-107\end{array}$ & $\begin{array}{l}164 \\
168\end{array}$ & $\begin{array}{l}123-283 \\
147-201\end{array}$ & $\begin{array}{r}8 \cdot 6 \\
10 \cdot 7\end{array}$ & $\begin{array}{l}3 \cdot 8-20 \cdot 1 \\
6 \cdot 4-16 \cdot 5\end{array}$ \\
\hline (C) Late follicular & $\left\{\begin{array}{l}\text { Ovulatory (all) } \\
\text { Luteinising hormone surge } \\
\text { No luteinising hormone surge } \\
\text { Anovulatory }\end{array}\right.$ & $\begin{array}{r}11 \\
5 \\
6 \\
7\end{array}$ & $\begin{array}{l}7 \cdot 7 \\
8 \cdot 0 \\
7 \cdot 5 \\
6 \cdot 4\end{array}$ & $\begin{array}{l}5-11 \\
6-11 \\
5-9 \\
3-10\end{array}$ & $\begin{array}{l}59 \\
59 \\
58 \\
67\end{array}$ & $\begin{array}{l}39-80 \\
39-76 \\
41-80 \\
49-80\end{array}$ & $\begin{array}{l}153 \\
164^{\star} \\
145 \\
162\end{array}$ & $\begin{array}{l}130-182 \\
156-182 \\
130-170 \\
144-177\end{array}$ & $\begin{array}{r}16 \cdot 8 \\
36 \cdot 6 \\
8 \cdot 7 \\
13 \cdot 9\end{array}$ & $\begin{array}{r}5 \cdot 6-56 \cdot 7 \\
26 \cdot 0-56 \cdot 7 \\
5 \cdot 6-15 \cdot 1 \\
9 \cdot 0-20 \cdot 5\end{array}$ \\
\hline (D) Luteal/second half of cycle \{ & $\left\{\begin{array}{l}\text { Ovulatory } \\
\text { Anovulatory }\end{array}\right.$ & $\begin{array}{r}13 \\
7\end{array}$ & $\begin{array}{l}5 \cdot 1 \\
5 \cdot 9\end{array}$ & $\begin{array}{l}2-9 \\
3-9\end{array}$ & $\begin{array}{l}85 \\
75\end{array}$ & $\begin{array}{l}42-125 \\
39-103\end{array}$ & $\begin{array}{l}223 \\
209\end{array}$ & $\begin{array}{l}138-448 \\
157-278\end{array}$ & $\begin{array}{l}6.4 \\
6.6\end{array}$ & $\begin{array}{l}2 \cdot 9-14 \cdot 2 \\
1 \cdot 7-39 \cdot 5\end{array}$ \\
\hline $\begin{array}{c}\text { Significance of differences amo } \\
\text { Ovulatory }\left\{\begin{array}{l}p<0.05 \\
p<0.01\end{array}\right. \\
\text { Anovulatory }\left\{\begin{array}{l}p<0.05 \\
p<0.01\end{array}\right.\end{array}$ & mong cycle stagest: & & \multicolumn{2}{|c|}{$\begin{array}{l}\text { (D) } v(\mathrm{~A}) \\
(\mathrm{D}) v(\mathrm{~B}),(\mathrm{D}) v(\mathrm{C}) \\
(\mathrm{B}) v(\mathrm{~A})\end{array}$} & \multicolumn{4}{|c|}{$\begin{array}{l}\text { (B) } v(\mathrm{~A}),(\mathrm{C}) v(\mathrm{~A}) \\
(\mathrm{D}) v(\mathrm{~B}),(\mathrm{D}) v(\mathrm{C}) \\
(\mathrm{B}) v(\mathrm{~A}),(\mathrm{C}) v(\mathrm{~A}),(\mathrm{D}) v(\mathrm{~B}) \\
\quad(\mathrm{D}) v(\mathrm{C})\end{array}$} & & \\
\hline
\end{tabular}

*Compared with non-luteinising hormone surge group $\mathrm{p}<0.04$.

†Numbers of peaks compared by Wilcoxon's signed ranks test; interpeak intervals and peak amplitudes compared by paired $t$ test. 
pulse generator from the preceding luteal stage, which takes a variable time to be reactivated even though serum progesterone concentrations may have fallen dramatically.

One study concluded that increased gonadotrophin releasing hormone secretion is important for initiation and maintenance of the preovulatory discharge of luteinising hormone. ${ }^{9}$ The luteinising hormone pulse frequency, however, was not compared with other stages of the same cycle in the same subjects. Though our results are qualitatively similar to those of Djahanbakhch et al, ${ }^{9}$ our detailed analysis showed no increase in pulse frequency of luteinising hormone during that part of the luteinising hormone surge that was captured compared with the mid-follicular stage of the same cycles or, indeed, with the late follicular stage of other subjects with similar follicular development and oestradiol production in whom surge luteinising hormone values were not found. We conclude that there is no alteration of activity in the gonadotrophin releasing hormone pulse generator in the preovulatory period of human ovulatory cycles. Thus the luteinising hormone surge in man appears to result entirely from the stimulatory action of oestradiol on the pituitary to render it more sensitive to the same gonadotrophin releasing hormone stimulus that is perceived by the pituitary during earlier stages of follicular development. Our data in man therefore support the view of Knobil, derived from studies in monkeys, ${ }^{1}$ that the gonadotrophin releasing hormone pulse generator plays a permissive rather than primarily regulatory part in the genesis of normal ovulatory cycles.

The luteinising hormone interpulse interval in the luteal stage was greater than that during any follicular stage in the ovulatory subjects. Slowing of the gonadotrophin releasing hormone pulse generator during the luteal stage of the cycle has generally been assumed to be due to the high oestrogen and progesterone environment of this stage. This view is supported by Soules et al, who reproduced luteal stage luteinising hormone profiles during the follicular stage with progesterone treatment. ${ }^{18}$ Luteinising hormone profiles from the early follicular stage and second half of the cycle in anovulatory subjects, however, frequently conformed to those of the luteal stage of ovulatory cycles, even though serum progesterone concentrations were very low and oestradiol values were less than half those found in luteal stages of ovulatory cycles. This evidence suggests that the high ovarian steroid hormonal environment is not critical for inhibition of the gonadotrophin releasing hormone pulse generator during the luteal stage of ovulatory cycles. Furthermore, the fact that the luteinising hormone pulse profiles of the anovulatory cycles were qualitatively similar to and quantitatively indistinguishable from comparable stages of ovulatory cycles, despite deficient ovarian steroidogenesis, indicates that an abnormal hypothalamic gonadotrophin releasing hormone pulse generator is not primarily responsible for disordered ovarian function in this subgroup of anovulatory subjects. The results from the anovulatory cycles suggest that a primary ovarian abnormality with an inadequate response to apparently normal pulsatile luteinising hormone secretion is responsible for the anovulation.

The anovulatory cycles were associated with a normal menstrual rhythm and a heterogeneous pattern of ovarian follicular development always associated with poor oestrogen production. This may be due to the lower follicle stimulating hormone concentrations in the early follicular stage when adequate stimulation by this hormone is essential for granulosa cell proliferation in the follicle destined for progression to a preovulatory state. In this respect only these subjects resemble those with chronic anovulation due to polycystic ovarian disease whose luteinising hormone interpulse interval is between 50 and 70 minutes ${ }^{1619} 20$-that is, similar to our results during all follicular stages of ovulatory and anovulatory cycles in women with regular menses. Our own data ${ }^{21}$ are similar and support the conclusion of no major abnormality in the gonadotrophin releasing hormone pulse generator in patients with chronic anovulation and oligoamenorrhoea due to the polycystic ovarian syndrome, again suggesting that this is not a major determinant of the pathological process.

We conclude that there is a wide range of activity of the hypothalamic gonadotrophin releasing hormone pulse generator in regularly menstruating women that is compatible with normal ovulation. Provided that the hypothalamus produces a gonadotrophin releasing hormone signal every $40-120$ minutes spontaneous ovulation occurs if oestradiol is produced from the ovary to enable the pituitary to generate a surge of luteinising hormone. Changes in hypothalamic gonadotrophin releasing hormone secretory function are not responsible for the anovulatory cycles in this subset of women with regular menstruation.

We are indebted to B $M$ Morton and $E$ Meredith for fastidiousness with sampling procedures and to $\mathrm{Dr} G$ Holder for steroid hormone assays. This work was supported in part by a grant from the West Midlands Regional Health Authority. A more detailed version of this paper and copies of the peak detection scheme algorithm may be obtained from Dr Clayton.

\section{Appendix}

\section{PEAK DETECTION SCHEME}

Our scheme for detecting pulses in serial samples of luteinising hormone rests on two basic ideas. Firstly, a peak is regarded as a value that dominates - that is, is numerically greater than-one or more of the values surrounding it by at least a certain amount. Secondly, the peak height must exceed the known random (within assay) component of data variability enough to render it unlikely to be due to chance fluctuation alone. The span of a peak is the number of values before and after that it exceeds; a nadir is a data minimum, defined by analogy with a peak; AMPLIN and MINAMP are parameters which control respectively the average (left-right) and minimum acceptable heights of peaks.

Briefly, the peak detection scheme works in an iterative manner. A trial set of peaks and nadirs is found. Any peak whose amplitude, calculated as the average distance between peak and the immediately preceding and succeeding nadirs, is smaller than a fixed number of standard deviations is rejected. The process is repeated until the set of peaks and nadirs is stable. Finally, spans, amplitudes, and interpeak intervals are recorded.

The algorithm is carried out in steps, as follows:

(1) Take natural logarithms of the luteinising hormone data.

(2) Find an initial set of peaks and their spans. Span must be between one and MAXSPAN (typical value of MAXSPAN $=25$, or half the length of the series): Nadirs are not examined at this stage.

(3) For each peak with its span find a trial nadir with the same or a larger span. If no such nadir exists reduce the span for the peak by one; if span is greater than zero repeat step (3) until a nadir is found, otherwise delete the peak from the initial set and go to step (7).

(4) Calculate the mean log luteinising hormone value of the preceding and succeeding nadirs and subtract it from the peak value. Call this difference AMP1. Calculate AMP2 as minimum of (peak minus left nadir) and (peak minus right nadir).

(5) Estimate SP, the standard deviation of the peak value (method discussed below).

(6) If $A M P 1>S P \times A M P L I M$ and AMP2 $>S P \times M I N A M P$ accept the peak. If either test fails reduce the span by one and go to step (3).

(7) If any peaks remain select next peak and go to step (3).

(8) This is the end of one iteration (cycle through the algorithm). If any peak deletions have occurred since the last iteration repeat from step (3) at the first peak of the current set. Otherwise stop.

The parameters AMPLIM and MINAMP are crucial to the performance of the algorithm. AMPLIM and MINAMP set lower limits on the peak size relative to the average of both nadirs and to the higher nadir respectively. Both restrictions were important in practice. In order to select sensible values the algorithm was applied repeatedly to series consisting of computer simulated "white noise" (pseudorandom samples from a Gaussian distribution with mean zero and standard deviation one). AMPLIM and MINAMP were varied systematically over a range. A specified type I error (false positive rate) of $5 \%$ was achieved with AMPLIM $=3.0$ and MINAMP $=2 \cdot 0$. Using these values a mean of $2 \cdot 5$ peaks were expected to occur by chance in an eventless eight hour series of 4910 minute samples.

The value chosen for MINAMP was not critical for white noise, as in this case 'peaks were expected to be roughly symmetrical. Peaks in luteinising hormone series are often asymmetrical, however, and we wished to guard against accepting as peaks values with a large amplitude on one side but only a small amplitude ("blip") on the other.

\section{Estimation of coefficient of variation}

The serum pool from each eight hour series was divided into 10 samples which were assayed in duplicate with each main assay. In order to estimate 
the intra-assay variability associated with a luteinising hormone value analysis of covariance of the standard deviation of each set of 10 quality control values was carried out. Data were log transformed before analysis. Covariates were assay-that is, subject-mean log luteinising hormone value (linear term), square of mean log luteinising hormone value (quadratic term), and interactions. Assay $\times$ linear and assay $\times$ quadratic terms were not statistically significant; so only two coefficients were required. Assays did differ significantly, so a separate "intercept" was needed for each. The final model for $\log S D$, given $X$, the mean $\log$ luteinising hormone value, and $Y$, the assay intercept, was: $S D$ (of log quality control values) $=\exp (\mathrm{Y}-1 \cdot 243 \mathrm{X}$ $+0 \cdot 2235 \mathrm{X}^{2}+$ residual)

It is worth pointing out that the above method provides an individual estimate of SD for each putative log peak value. In general small peaks (in original units) had smaller absolute SDs than large peaks.

Note that the SD of log data may be shown to correspond roughly to the coefficient of variation of the raw data.

\section{Validation of algorithm; comparison with other methods}

The question of the false positive rate of the peak detection scheme is discussed above. In order to establish the type II (false negative) error rate we should need to know the "true picture"-that is, the actual pattern of peaks-in the series. As almost by definition this is never known explicitly, validation would have to be by computer simulation using appropriate mathematical models of luteinising hormone series. We do not know of the existence of such models. Anyway the validation would be only as good as the model:

Our main criterion when developing the peak detection scheme was "Do the results look right?" on inspecting plots of the raw data. We rejected several earlier versions because the "peaks" were subjectively implausible. The MINAMP criterion was included because without it clearly erroneous peaks were being "detected."

On this basis the Merriam and Wachter PULSAR algorithm ${ }^{12}$ frequently failed to give subjectively satisfactory peaks. Usually it was insensitive. It did not prove possible to calibrate it in such a way as to produce convincing results.

Santen and Bardin's method, ${ }^{14}$ or a modification of it, is often cited, but careful study of their paper does not give enough information to enable it to be translated into a computer algorithm without making several assumptions. Their basic principle is to look for a $20 \%$ rise above a nadir, though this seems quite arbitrary and crude. No rigorous definition of peaks and nadirs was given, nor any estimate of the false positive rate that might be expected.

We rejected the Clifton and Steiner algorithm ${ }^{22}$ because it has been shown to fail where series comprise both large and small amplitude peaks, as during the luteal stage of the cycle. ${ }^{6}$

We tried the periodogram method of Murdoch et $a l .{ }^{13}$ This is an attempt to break down the luteinising hormone pulsatility pattern into its major frequencies, each with their amplitude. Unfortunately, presumably owing to the unstable nature of the luteinising hormone signal, the periodograms varied considerably even for the same subject and cycle stage. It was hard to extract meaningful summary statistics.

\section{References}

1 Knobil E. The neuroendocrine control of the menstrual cycle. Recent Prog Horm Res 1980;36: 53-88.

2 Clayton RN. The neuroendocrinology of reproductive disorders. In: Lightman SL, Everitt B, eds. Contemporary neuroendocrinology. Oxford: Blackwell, 1986:563-87.

Clayton RN. GnRH: from physiology to pharmacology. Clin Endocrinol 1987;26:361-84. 4 Backstrom CT, McNeilly AS, Leask RM, Baird DT. Pulsatile secretion of LH, FSH, prolactin, oestradiol and progestrone during the human menstrual cycle. Clin Endocrinol. 1982;17:29-42.

5 Fillcori $M$, Santoro N, Merriam GR, Crowley WF. Characterisation of the physiological pattern of episodic gonadotropin secretion throughout the human menstrual cycle. $\mathcal{f}$ Clin Endocrinol Metab 1986;62:1136-44.

6 Reame N, Sauder SE, Kelch RP, Marshall JC. Pulsatile gonadotropin secretion during the human menstrual cycle: evidence for altered frequency of gonadotropin releasing hormone secretion. f Clin Endocrinol Metab 1984;59:328-37.

7 Steele PA, McDonnell LF, Judd SJ. Activity of gonadotropin releasing hormone neurons during the preovulatory luteinising hormone surge. Fertil Steril 1986;45:179-84.

8 Veldhuis JD, Beitins IZ, Johnson ML, Serabian MA, Dufau ML. Biologically active luteinising hormone is secreted in episodic pulsations that vary in relation to stage of the menstrual cycle. J Clin Endocrinol Metab 1984;58:1050-8.

9 Djahanbakhch O, Warner P, McNeilly AS, Baird DT. Pulsatile release of LH and oestradiol during the periovulatory period in women. Clin Endocrinol 1984;20:579-89.

10 Mason $P$, Adams J, Morris DV, et al. Induction of ovulation with pulsatile luteinising hormone releasing hormone. $\mathrm{Br} M e d \mathcal{J}$ 1984;288:181-5.

11 Menon V, Butt WR, Clayton RN, Logan-Edwards R, Lynch SS. Pulsatile administration of GnRH for the treatment of hypogonadotrophic hypogonadism. Clin Endocrinol 1984;21: 223-32.

12 Merriam GR, Wachter KW. Algorithms for the study of episodic hormone secretion. Am $\mathcal{F}$ Physiol 1982;243E:310-8.

13 Murdoch AP, Diggle PJ, Dunlop W, Kendall-Taylor P. Determination of the frequency of pulsatile luteinising hormone secretion by time series analysis. Clin Endocrinol 1985;22:341-6.

14 Santen RJ, Bardin CW. Episodic luteinizing hormone secretion in man. Pulse analysis, clinical interpretation, physiologic mechanisms. $\mathcal{f}$ Clin Invest 1973;52:2617-28.

15 Eissa MK, Obhrai MS, Docker MF, Lynch SS, Sawers RS, Newton JR. Follicular growth and endocrine profiles in spontaneous and induced conception cycles. 'F ertil Steril 1986;45:191-5.

16 Burger CW; Korsen T, van Kessel H, van Dop PA, Caron FJM, Schoemaker J. Pulsatile luteinizing hormone patterns in the follicular phase of the menstrual cycle, polycystic ovarian luteinizing hormone patterns in the follicular phase of the menstrual cycle, polycystic ovarian
disease (PCOD) and non-PCOD secondary amenorrhea. $\mathcal{f}$ Clin Endocrinol Metab 1985;61: 1126-32.

17 Veldhuis JD, Evans WS, Johnson ML, Wills MR, Rogol AD. Physiological properties of the luteinising hormone pulse signal: impact of intensive and extended sampling paradigms on its characterisation in healthy men and women. $\mathcal{F}$ Clin Endocrinol Metab 1986;62:881-91.

18 Soules MR, Steiner RA, Clifton DK, Cohen NL, Aksel S, Bremner WJ. Progesterope modulatio of pulsatile luteinizing hormone secretion in normal women. $f$ Clin Endocrinol Metab 1984;58:378-83:

19. Laatikainen T, Tulenheimo A, Andersson B, Karkkainen J. Obesity serum steroid levels and pulsatile gonadotrophin secretion in polycystic ovarian disease. Eur f Obstet Gynecol Reprod Biol 1983;15:45-53.

20 Molloy BG, El Sheikh MAA, Chapman C, Oakey RE. Pathological mechanisms in polycystic ovary syndrome: modulation of LH pulsatility by progesterone. Br $f$ Obstet Gynaecol 1984;91:457-65.

21 Chapman AJ, Wilson MD, Obhrai M, et al. Effect of bromocriptine on LH pulsatility in the polycystic ovary syndrome. Clin Endocrinol (in press).

22 Clifton DK, Steiner RA. Cycle detection: a technique for estimating the frequency and amplitude of episodic fluctuations in blood hormone and substrate concentrations. Endocrinology 1983;112:1057-64.

(Accepted 28 May 1987)

\section{YEARS AGO}

The Boston Medical and Surgical fournal has recently contained some curious examples of rapid graduation. Dr Fisk mentions one young man who took up the study of the science and art of medicine and surgery at the beginning of last winter session (1886-7) at Denver University, and obtained a degree from a University in New England nine months and eight days later. In another case the first course or lectures was taken at the University of Ann Arbor, and in less than one year the young person was graduated. We may agree with one of the correspondents of our contemporary, that it is high time that some of the medical colleges of the United States turned over a new leaf. The clause in the Medical Act, 1886, which gives the Medical Council power to insert upon the Medical Register the names of persons holding medical degrees from foreign universities, gives the subject an interest to us which it has never had before. It has been amusing from time to time to read the almost incredible stories told by our American contemporaries of the ease and rapidity with which medical degrees are sometimes obtained on the other side, and the curious ignorance displayed by some of these machinemade graduates; now it becomes serious, and the action of the General Medical Council will be watched with interest. It will no doubt proceed with deliberation, and it is much to be hoped that it will demand the fullest and most precise information both as to the curriculum and examinations before granting registration. The Act requires the Medical Council to satisfy itself that the diploma or diplomas furnish "a sufficient guarantee of the possession of the requisite knowledge and skill for the efficient practice of medicine, surgery, and midwifery." That degrees of many of the universities in the United States do afford the necessary guarantee nobody will for a moment doubt; nay, all will recognise their high academical and professional value; but it would be only a false compliment to our American brethren, and in fact a slight on those who have there earned honourable degrees, to pretend to believe that all are to be placed on the same footing. (British Medical Fournal 1887;ii:523.) 